\title{
Analysis of the Prestress Transfer Bond Problem Incorporating Cohesive Cracking of Concrete
}

\section{R A Weerasekera}

\begin{abstract}
Accurate prediction of prestress transfer bond is a difficult task. A sound theoretical basis is lacking to complement the experimental evidence available in the literature. An analysis procedure treating cracked concrete as an anisotropic material is presented here. Using this approach, improved transfer length predictions can be made. An analytical solution for the formulated non-linear nonhomogeneous differential equation is not feasible. Hence a numerical solution obtained using a modified fourth order Runge- Kutta method as an initial value problem is successfully applied. The numerical results were found to be accurate and the solution technique efficient.
\end{abstract}

Keywords: Transfer bond, pretension, cracked concrete, uncracked concrete, isotropic analysis, anisotropic analysis, cohesive cracking, and transfer length.

\section{Introduction}

Pretensioned prestressed concrete beams have been in use for more than 70 years. Early practice made use of $2 \mathrm{~mm}$ wire but recent trends are towards use of 13,15 and $16 \mathrm{~mm}$ diameter strand in such pretensioned members There are several problems associated with prediction of transmission of prestress by bond. Experimental results on bond as related to large strand sizes are limited. An extensive experimental programme is also expensive. The absence of a valid theory to complement experiments has stifled the search for rational solutions to the bond problem.

In this paper a detailed procedure is presented to predict bond development. In this approach the complications resulting from the complex material properties of cracked concrete are resolved.

\section{Problem formulation}

\subsection{General}

To make an analysis possible, it is necessary to make some simplifying assumptions. Steel is treated as a solid cylinder and concrete as a hollow cylinder with a radius equal to the lesser of the smaller concrete cover or one-half the distance to the closest adjacent reinforcing. The outer surface of the notional concrete cylinder is assumed to behave as a free surface. The physical dimensions are shown in Fig. I, where the radius of the steel cylinder is equal to $r_{0}$, the radius of the unstressed steel. The concrete cylinder has as outer radius of $c$ and an inner radius of $r_{i}$ which is the radius of the stressed steel because the concrete is cast when the tendon is in its stressed state. Due to Poisson's ratio, $r_{j}$ is always less than $r_{i 1}$. At prestress transfer the steel shortens and swells so a pressure $p$ develops at the interface. The basic principle was already understood and described by Hoyer and Friedrich [1], but in their analysis an unconfined situation has been adopted. The resulting equation does not agree very well with test results.

An isolated steel part from the sliced element is shown in Fig. 2. The change of force in the steel is based on the assumption that a constant coefficient of friction can be assumed such that

$$
A_{b} \Delta f_{p z}=\mu\left(d_{b} \Delta z \pi\right) p
$$

Using thick cylinder theory as illustrated in 4Fig.1, expressions for stresses, strains and displacements can be developed by ensuring equilibrium and compatibility, and imposing boundary conditions and constitutive relationships that represent the material behaviour.

The equilibrium equations and straindisplacement equations are identical for both isotropic and anisotropic analysis.

Eng. Dr. I $R$ A Weerasekera is a Senior Lecturer at the Department of Civil Engineering, Liniversity of Moraluura, Moratuwa, Sri Lanka. He received his B.SC (Eng.) from University of Moratuura and PhD from The University of Calgary, Calgary, Alberta, Canada. He is also a Chartered Civil Engineer. His research interests are reinforced and prestressed concrete structures, computer aided analysis and design and bridge engineering. 


\subsection{Equilibrium Equation}

For the element shown in Fig. 3, equilibrium of forces in the radial direction, $r$, yields

$$
\sigma_{r}+\frac{\partial \sigma_{r}}{\partial r} r-\sigma_{\theta}+\frac{\partial \tau_{z r}}{\partial z} r=0
$$

In the longitudinal direction all variables are assumed to be independent of $z$, within the finite length $\Delta z$. Therefore the above equation reduces to

$\sigma_{r}-\sigma_{\theta}+\frac{d \sigma_{r}}{d r} r=0$

\subsection{Strain-displacement Equations}

These equations can be derived directly, using the element shown in Fig. 3, from considering a radial displacement of $u$ for the inner radius and $(u+d u)$ for the outer radius.

$$
\begin{aligned}
\varepsilon_{r} & =\frac{d u}{d r} \\
\varepsilon_{\theta} & =\frac{u}{r}
\end{aligned}
$$

\subsection{Compatibility}

The basic requirement to be fulfilled is the compatibility of displacement at the steelconcrete interface given by

$r_{o}+u_{o}=u_{j}+r_{j}$

where

$u_{o}$ - radial displacement of outer surface of steel cylinder

$u_{j}$-radial displacement of inner surface of concretecylinder

\subsection{Boundary condition}

For the concrete cylinder the assumption of an outer free surface corresponds to a radial stress, $\sigma_{r}$, equal to zero when $r=c$. This condition applies for all the cases discussed in this paper.

\subsection{Constitutive Relations}

The constitutive relations can only be meaningful if the material behaviour is represented adequately. In modelling the behaviour, the two materials were initially assumed to behave as homogeneous isotropic, liner elastic materials. These assumptions are valid for prestressing steel at the transfer stage as the steel is not stressed beyond its elastic limit. For concrete, however, the above assumptions are justifiable only if both tensile and the compressive stresses remain within the linear range.

To examine the state of stress and the validity of the assumptions, an isotropic elastic analysis was performed. An element in the form of a slice of thickness $\Delta z$ is taken at a distance $z$ from the end. The stresses in the longitudinal direction are $f_{p z}$ and $f_{c z}$ for the stresses in prestressing steel and concrete respectively. (A detailed derivation of the analysis and relevant equations for stresses, strain and displacement are found by Weerasekera [2]). The stresses and strains at every location must satisfy the basic stress strain equation:

$$
\left\{\begin{array}{l}
\varepsilon_{r} \\
\varepsilon_{\theta} \\
\varepsilon_{z}
\end{array}\right\}=\frac{1}{E}\left[\begin{array}{ccc}
1 & -v & -v \\
-v & 1 & -v \\
-v & -v & 1
\end{array}\right]\left\{\begin{array}{l}
\sigma_{r} \\
\sigma_{\theta} \\
\sigma_{z}
\end{array}\right\}
$$

\subsection{Radial and circumferential stresses for uncracked concrete}

Eq. (7) can be solved in terms of $\varepsilon_{r}, \varepsilon_{\theta}$ and $\varepsilon_{z}$ to find the stresses $\sigma_{r}$ and $\sigma_{\theta}$. The solution is slightly different than solution in standard text books because it is based on two strains and one stress.

Radial Stress

$$
\sigma_{r}=\frac{E}{\left(1-v^{2}\right)}\left\{\varepsilon_{r}+v \varepsilon_{\theta}\right\}+\frac{v(1+v) \sigma_{z}}{\left(1-v^{2}\right)}
$$

Circumferential Stress

$$
\sigma_{\theta}=\frac{E}{\left(1-v^{2}\right)}\left\{\varepsilon_{\theta}+v \varepsilon_{r}\right\}+\frac{v(1+v) \sigma_{z}}{\left(1-v^{2}\right)}
$$

\subsection{Analytical solution for $u$}

Using Eq. (4), (5), (8) and (9) in equilibrium Eq. (3), the usual differential equation can be obtained.

$$
\frac{d}{d r}\left\{\frac{1}{r}\left[\frac{d}{d r}(u r)\right]\right\}=0
$$

An analytical solution is available for this differential equation

$u=c_{1} r+\frac{c_{2}}{r}$

Using these Eq. in (4) and (5) and then in Eq. (8) and (9), it is possible to show 
$\sigma_{r}=E\left\{\frac{c_{1}}{(1-v)}-\frac{c_{2}}{r^{2}(1+v)}\right\}+\frac{v \sigma_{z}}{(1-v)}$

$\sigma_{\theta}=E\left\{\frac{c_{1}}{(1-v)}+\frac{c_{2}}{r^{2}(1+v)}\right\}+\frac{v \sigma_{z}}{(1-v)}$

The constants $c_{1}$ and $c_{2}$ are determined using the specific boundary conditions.

\section{General equations for stresses and displacements for uncracked regions}

\subsection{CASE (a) Solid Steel Cylinder}

When $r=0, u=0$, Therefore for all $r$

$\sigma_{r}=\sigma_{\theta}=f_{r}$,

Using the expression for constants in Eq. (11), displacement can be determined as

$u=\left[\frac{f_{r}(1-v)-v \sigma_{z}}{E}\right] r$

\subsection{CASE (b) Hollow Uncracked Concrete Cylinder}

When $r=R, \sigma_{r}=f_{r}$ and when $r=c, \sigma_{r}=0$.

Therefore the following equations can be obtained.

$$
\begin{aligned}
& \sigma_{r}=\frac{f_{r}\left(1 / c^{2}-1 / r^{2}\right)}{\left(1 / c^{2}-1 / R^{2}\right)} \\
& \sigma_{\theta}=\frac{f_{r}\left(1 / c^{2}+1 / r^{2}\right)}{\left(1 / c^{2}-1 / R^{2}\right)} \\
& u=\frac{f_{r} r}{E\left(1 / c^{2}-1 / R^{2}\right)}\left[\frac{(1-v)}{c^{2}}+\frac{(1+v)}{r^{2}}\right]-\frac{v \sigma_{z} r}{E}
\end{aligned}
$$

$$
\frac{d u}{d r}=\frac{f_{r}}{E\left(1 / c^{2}-1 / R^{2}\right)}\left[\frac{(1-v)}{c^{2}}-\frac{(1+v)}{r^{2}}\right]-\frac{v \sigma_{z}}{E}
$$

\subsection{CASE (c) Uncracked portion of Hollow} Partially Cracked Concrete Cylinder

When $\quad r=R, \sigma_{\theta}=f_{\theta}$ and when

$r=c, \sigma_{r}=0$. Therefore we obtain

$\sigma_{r}=\frac{f_{\theta}\left(1 / c^{2}-1 / r^{2}\right)}{\left(1 / c^{2}+1 / R^{2}\right)}$

$$
\begin{aligned}
& \sigma_{\theta}=\frac{f_{\theta}\left(1 / c^{2}+1 / r^{2}\right)}{\left(1 / c^{2}+1 / R^{2}\right)} \\
& u=\frac{f_{\theta} r}{E\left(1 / c^{2}+1 / R^{2}\right)+}\left[\frac{(1-v)}{c^{2}}+\frac{(1+v)}{r^{2}}\right]-\frac{v \sigma_{z} r}{E}
\end{aligned}
$$

$$
\frac{d u}{d r}=\frac{f_{\theta}}{E\left(1 / c^{2}+1 / R^{2}\right)}\left[\frac{(1-v)}{c^{2}}-\frac{(1+v)}{r^{2}}\right]-\frac{v \sigma_{z}}{E}
$$

\subsection{Equation for Displacement and Contact Pressure}

For steel cylinder, the displacement at its outer surface can be written from Eq. (15)

$u_{o}=\frac{-p\left(1-v_{p}\right) r_{o}}{E_{p}}-v_{p} \frac{f_{p z}}{E_{p}} r_{o}$

For the uncracked concrete cylinder, the displacement at its inner surface is given by Eq.(18) as

$$
u_{j}=\frac{-p r_{j}}{E_{c}\left(\frac{1}{c^{2}}-\frac{1}{r_{j}^{2}}\right)}\left[\left(\frac{1-v_{c}}{c^{2}}\right)+\left(\frac{1+v_{c}}{r_{j}^{2}}\right)\right]-\frac{v_{c} f_{c z}}{E_{c}} r_{j}
$$

Using these displacements in the compatibility Eq. (6) an expression can be obtained for the interface pressure as:

$$
p=\frac{r_{o}\left(1-v_{p} f_{p z} / E_{p}\right)-r_{j}\left(1-v_{c} f_{c z} / E_{c}\right)}{\left(1-v_{p}\right) r_{o} / E_{p}+\left[v_{c}+\left(c^{2}+r_{j}^{2}\right) /\left(c^{2}-r_{j}^{2}\right)\right] r_{j} / E_{c}}
$$

Using this value of $p$ as the stress $f_{r}$ in Eq. (16) and (17) it is possible to obtain the stresses in the both radial and circumferential directions. The theoretical analysis shows that over much of the transfer length the tensile stresses in the circumferential direction adjacent to the steel exceed the concrete tensile strength. Therefore it is clear that the concrete must crack in the radial direction and the behaviour becomes anisotropic. Three possible situations need to be considered along the transfer length. These will be referred to as uncracked (case I), partially cracked (case II) and fully cracked (case III) as shown in Fig. 4.

Tepfers [3] used a simple model for the identification of cracking in reinforced 
concrete but the effect of circumferential stresses in the cracked region was not taken into consideration.

\section{Anisotropic elastic analysis for concrete with radial cracking}

\subsection{Constitutive Relations}

The equilibrium equations and strain displacement equations in Eq. (3) to (6) are identical for both the isotropic and anisotropic analysis. However, the constitutive relations differ. The conditions for the anisotropic state can be written in the following general form.

$$
\left\{\begin{array}{c}
\varepsilon_{r} \\
\varepsilon_{\theta} \\
\varepsilon_{z}
\end{array}\right\}=\left[\begin{array}{ccc}
1 / E_{r} & -v_{\theta r} / E_{\theta} & -v_{z r} / E_{z} \\
-v_{r \theta} / E_{r} & 1 / E_{\theta} & -v_{z \theta} / E_{z} \\
-v_{r z} / E_{r} & -v_{\theta z} / E_{\theta} & 1 / E_{z}
\end{array}\right]\left\{\begin{array}{c}
\sigma_{r} \\
\sigma_{\theta} \\
\sigma_{z}
\end{array}\right\}
$$

For a stratified material, with $\theta$ as the direction normal to the plane of stratification $(r-z)$, the anisotropic elastic properties reduce to the following:

$$
E_{r}=E_{z}=E_{c}
$$

$E_{\theta}$ is a function of $r$ that can be chosen to fit the particular conditions.

$$
\begin{aligned}
& E_{\theta}=g(r) \\
& v_{r z}=v_{z r}=v_{z \theta}=v_{r \theta}=v_{c} \\
& v_{\theta r}=v_{\theta z}=v_{c} \frac{E_{\theta}}{E_{c}}
\end{aligned}
$$

It is instructive to examine a region in the vicinity of a crack presented by Hillerborg [4]. This type of cracking subsequently termed as "cohesive cracking" by Weerasekera and Loov [5], continues to transmit some tension across the crack. The length of the cracked zone $\left(L_{c}\right)$ is defined as the distance measured from the effective crack tip to the surface of the steel. To represent the degree of cracking, two parameters, the reduced maximum tensile strength $\left(f_{t r}\right)$ and the reduced effective circumferential modulus are important.

The reduced modulus of elasticity in the $\theta$ direction $\left(E_{\theta}\right)$ is determined using a stress crack-width curve based on experiment [2], successfully matched this curve as rectangular hyperbola for this analysis, by utilizing the experimental result [6]. This can be done without referring to a particular gauge length. For this particular problem it was assumed that three cracks would be sufficient to allow the tendon to expand.

Substituting these values into Eq. (27), the following equation can be obtained.

$$
\left\{\begin{array}{l}
\varepsilon_{r} \\
\varepsilon_{0} \\
\varepsilon_{z}
\end{array}\right\}=\frac{1}{E_{c}}\left[\begin{array}{ccc}
1 & -v_{c} & -v_{c} \\
-v_{c} & \frac{E_{c}}{E_{\theta}} & -v_{c} \\
-v_{c} & -v_{c} & 1
\end{array}\right]\left\{\begin{array}{l}
\sigma_{r} \\
\sigma_{\theta} \\
\sigma_{z}
\end{array}\right\}
$$

\subsection{Radial and Circumferential Stresses for Cracked Concrete}

Solving Eq. (32) in terms of strain $\varepsilon_{r}$ and $\varepsilon_{\theta}$ and stresses $\varepsilon_{z}$, stresses can be expressed as

Radial Stress

$\sigma_{r}=\frac{E_{c}}{\left(E_{c}-v_{c}^{2} E_{\theta}\right)}\left[E_{c} \varepsilon_{r}+v_{c} E_{\theta} \varepsilon_{\theta}\right]+\frac{v_{c}\left(E_{c}+v_{c} E_{\theta}\right) \sigma_{z}}{\left(E_{c}-v_{c}^{2} E_{\theta}\right)}$

Circumferential stress

$$
\sigma_{\theta}=\frac{E_{c} E_{\theta}}{\left(E_{c}-v_{c}^{2} E_{\theta}\right)}\left[v_{c} \varepsilon_{r}+\varepsilon_{\theta}\right]+\frac{v_{c} E_{\theta}\left(1+v_{c}\right) \sigma_{z}}{\left(E_{c}-v_{c}^{2} E_{\theta}\right)}
$$

\subsection{Governing Equation for Radial Displacement}

The solution for $u$ using Eq. (33) and (34), combined with the equilibrium Eq. (3) the following differential equation can be obtained.

$$
\begin{gathered}
r E_{c}^{2}\left[E_{c}-v_{c}{ }^{2} E_{\theta}\right] \frac{d^{2} u}{d r^{2}}+E_{c}{ }^{2}\left[E_{c}+r v_{c}{ }^{2} E_{\theta}^{\prime}-v_{c}{ }^{2} E_{\theta}\right] \frac{d u}{d r} \\
+E_{c}\left[r E_{c} v_{c} E^{\prime}{ }_{\theta}-E_{\theta}\left(E_{c}-v_{c}{ }^{2} E_{\theta}\right)\right] \frac{u}{r} \\
+\left[\left(E_{c}-v_{c}{ }^{2} E_{\theta}\right)\left(E_{c}-E_{\theta}\right)+r v_{c} E_{c}\left(1+v_{c}\right) E_{\theta}^{\prime}\right] \sigma_{z} v_{c}=0
\end{gathered}
$$

Eq. (35) above is a $2^{\text {nd }}$ order nonlinear nonhomogeneous equation. Therefore an analytical solution is not feasible so this equation must be solved using a numerical procedure. 


\section{Numerical solution procedure}

\section{$5.1(\mathrm{R}-\mathrm{K})^{4}$ Method}

The solution is slightly different than the solutions found in standard text books such as reference [7], because it is based on radial increments of $r$.

To use the numerical technique, the $4^{\text {th }}$ order Runge- Kutta (R-K) method [7] (as an initial value problem), Eq.(35) is rearranged to the following form:

$u^{\prime \prime}=f\left(u^{\prime}, u, r\right)$

ie. $\frac{d^{2} u}{d r^{2}}=\delta\left\{\alpha \frac{d u}{d r}+\beta \frac{u}{r}+\gamma\right\}$

Where

$$
\begin{aligned}
& \delta=1 /\left[r E_{c}^{2}\left(E_{c}-v_{c}^{2} E_{\theta}\right)\right] \\
& \alpha=E_{c}^{2}\left[v_{c}^{2} E_{\theta}-E_{c}-r v_{c}^{2} E_{\theta}^{\prime}\right] \\
& \beta=E_{c}\left[E_{\theta}\left(E_{c}-v_{c}^{2} E_{\theta}\right)-r E_{c} v_{c} E_{\theta}^{\prime}\right] \\
& \gamma=\left[\left(E_{c}-v_{c}^{2} E_{\theta}\right)\left(E_{\theta}-E_{c}\right)-r v_{c} E_{c}\left(1+v_{c}\right) E_{\theta}^{\prime}\right] v_{c} \sigma_{z}
\end{aligned}
$$

\subsection{Auxiliary Terms}

If initial values are $u_{n}^{\prime}, u_{n}, r_{n}$ and the step size is $t$, then the following auxiliary terms can be computed in sequence:

$$
\begin{aligned}
& A_{n}=\frac{1}{2} t f\left(u_{n}^{\prime}, u_{n}, r_{n}\right) \\
& \beta_{n}=\frac{1}{2} t\left(u_{n}^{\prime}+\frac{1}{2} A_{n}\right) \\
& B_{n}=\frac{1}{2} t f\left(u_{n}^{\prime}+A_{n}, u_{n}+\beta_{n}, r_{n}+\frac{1}{2} t\right) \\
& C_{n}=\frac{1}{2} t f\left(u_{n}^{\prime}+B_{n}, u_{n}+\beta_{n}, r_{n}+\frac{1}{2} t\right) \\
& \delta_{n}=t\left(u_{n}^{\prime}+C_{n}\right) \\
& D_{n}=\frac{1}{2} t f\left(u_{n}^{\prime}+2 C_{n}, u_{n}+\delta_{n}, r_{n}+t\right) \\
& K_{n}=\frac{1}{3}\left(A_{n}+B_{n}+C_{n}\right) \\
& K_{n}^{*}=\frac{1}{3}\left(A_{n}+2 B_{n}+2 C_{n}+D_{n}\right)
\end{aligned}
$$

Updated values after the increment The values at the end of the step are

$$
u_{n+1}^{\prime}=u_{n}^{\prime}+k_{n}^{*}
$$

$$
\begin{aligned}
& u_{n+1}=u_{n}+t\left(u_{n}^{\prime}+K_{n}\right) \\
& r_{n+1}=r_{n}+t
\end{aligned}
$$

\subsection{Application to Partially Cracked Region}

Initially condition can be obtained by choosing $L_{c}$ (Cracked length for partially cracked case) or $f_{t r}$ (for maximum reduced tensile strength for fully cracked case) and using in Eq. (20) to get $\sigma_{r}$, Eq. (21) to get $\sigma_{\theta}$, Eq. (22) to get $u$

By repeating the procedure with $u_{n+1}^{\prime}, u_{n+1}, r_{n+1}$ as new initial values and so on, with a suitable number of steps these quantities at the inner radius can be found. The step by step analysis can be carried out for increments of $\Delta z$ from the free end until the steel stress reaches $f_{p i}$ the initial prestress after transfer where the bond stress is zero. In this process the stress in prestressing steel is transferred to the concrete including the incremental change that occurs within the finite length $\Delta \mathrm{z}$.

\section{Calibration}

In order to calibrate the theoretical analysis an experimental study was performed to establish the coefficient of friction of the interface. The properties and parameters of three groups of test beams [2] are shown in Table 1. Each group of strain measurement was made up of eight or twelve readings from the two sides and two ends of the two or three beams in each group.

\subsection{Determination of Transfer Length}

The estimation of the transfer length using concrete strains has to be based on some objective criterion because the full prestress is obtained only after a long gradual transition. Unfortunately many researchers have not been explicit in defining this length. In this paper the following approach to define the transfer length has been made. The strain corresponding to the shrinkage strain plus $90 \%$ of the increased strain is determined. Then a line is drawn through the shrinkage strain at the end and the $90 \%$ intersection. This line is then extrapolated to intersect the maximum strain. The distance from the end to this intersection point is considered to be the transfer length, as shown in Fig. 5. For practical application this method defines the transfer length appropriately. 


\subsection{Comparison of Theoretical with Experimental}

Measured and theoretical transfer lengths for three groups of beams with clearly defined covers are compared in Table 2. It was observed that use of a coefficient of friction of 0.75 along with an assumed concrete tensile strength of $0.6 \sqrt{f_{c i}^{\prime}}$ gave theoretical results that closely matched the experimental measurements. The theoretical and experimental strain curves for typical cases are shown in Fig. 6, 7 and 8. It can be seen that these curves match very well.

\section{Predicted prestress build-up curves}

After calibration with the test results the proposed numerical procedure was used in a comprehensive study, to generate data to predict the influence of other variables. The data used are given in Table 3 . The influence of longitudinal stress, $f_{c e}$, in the concrete was found to be negligible. The range of values chosen for the variables is typical of that commonly used in practice. The conclusions drawn from the analysis of the data are limited to the following ranges of values.

$$
\begin{aligned}
& 20 \leq c_{y} \leq 40 \mathrm{~mm} \\
& 9.53 \leq d_{b} \leq 15.24 \mathrm{~mm} \\
& 20 \leq f^{\prime}{ }_{c i} \leq 40 \mathrm{MPa} \\
& 900 \leq f_{p i} \leq 1300 \mathrm{MPa}
\end{aligned}
$$

Variations of the predicted prestress profile are shown in Fig. 9 and 10 for $15.24 \mathrm{~mm}$ strands. For $9.53 \mathrm{~mm}$ strands the spread of curves is very much less. The analysis is very sensitive to small incremental changes in the steel diameter. Irregularities or surface roughness, which might produce an effective increase of diameter during slip are likely to be of great importance. A value of $\mu$ equal to 0.75 matches test results. This calibration is used throughout the analysis.

\subsection{Average Cover}

To define the concrete cylinder, an average cover is required when multiple tendons or variable covers are present. The most appropriate value for the average cover is not obvious at this time. However it is clear that the average cover is between the minimum and maximum covers

However, comparison of results with those in the literature is difficult as the average cover cannot be readily established when the covers vary on different sides. This is especially difficult when there are multiple strands.

\section{Discussion}

The radial pressure at the interface is converted to bond stress using a friction interface. The associated friction coefficient is a property of the type of prestressing steel and its surface condition. A coefficient of friction of 0.75 has been used to generate the theoretical curves. This value is used throughout the analysis. Usually all 3 cases defined in Fig. 4 (namely I, II, and III) appear as shown in Fig. 9 and 10 . The fully cracked zone will not occur when the tendons have a large cover. The shape of the prestress build-up profile can have concave, linear or convex portions as shown in Fig. 9 and 10. These zones are shown in Fig. 11 as a general diagram for clarity.

\section{Conclusions}

1. When a tendon is released, the concrete near the end of the tendon may become fully cracked. The concrete surrounding the tendon further along will be partially cracked and near the end of the transfer zone will be uncracked.

2. The shapes of the prestress build-up profiles vary throughout the transfer zone. These can have concave, linear or convex portion as shown.

3. Computations show that the partially cracked region is the most important one as most of the prestress transfer occurs in this zone.

4. The expected width of cracks in the transfer zone falls within what might be called the "cohesive cracking" range. Tensile stresses therefore continue to be transferred across these cracks.

5. Modelling of the cohesive cracking zone as an anisotropic material has been achieved and a solution derived using a numerical procedure.

6. Based on the theoretical analysis that has been developed, the bond strength depends on the concrete strength, the tendon stress, size, cover and spacing, and the location along the transfer length.

7. The theory developed in this work successfully describes the stress and strain state in the prestress transfer bond region. The effect of changes to one or more of the variable can therefore be predicted.

8. The proposed procedure seems to unravel the influences of the parameters that affect stress development in the prestress transfer zone 


\section{References}

1. Hoyer, E., und Friedrich, E., "Beitrag zur Frage der Stahlsaitenbeton”, Berlin, Leipzig, Elsner, Haftspannung in Eisenbeton-bauteilen, Beton und Eisen, Vol 38/6 - 1939, pp. 107-110.

2. Weerasekera, I.R.A., "Transfer and Flexural Bond in Pretensioned Prestressed Concrete", Ph.D. Thesis, Department of Civil Engineering, The University of Calgary, Calgary, Canada 1991, pp 1-322.

3. Tepfers, R., "Cracking of Concrete Cover along Anchored Deformed Reinforcing Bars", Magazine of Concrete Research, Vol.31, No. 106, March 1979, pp 3-12

4. Hillerborg, A., "Analysis of One Single Crack", Fracture Mechanics of Concrete, Developments in Civil Engineering, 7, Editor F.H.Wittmann, Elsevier Science Publishers, Amsterdam, The Netherlands, 1983, pp 233- 249.

5. Weerasekera, I.R.A., and Loov, R.E., "Prestressed Transfer Length Predicted by Cohesive Crack Model", Proceedings of the International Conference on Micro- Mechanics of Failure of Quasi-Brittle Materials, Albuquerque, New Mexico, USA, June, 1990, pp 417-426.

6. Gopalaratnam, V.S., and Shah, S.P., " Softening Response of Plain Concrete in Direct Tension", ACI Journal, Vol.82, No.3, May-June 1985, pp.310-323.

7. Kreyszig, E., "Advanced Engineering Mathematics", $5^{\text {th }}$ Edition, John Wiley \& Sons, New York, 1983, pp 1097.

\section{NOTATION}

$A_{b}=$ area of prestressing steel

$c=$ radius of outer surface concrete

$c_{y}=$ concrete cover to surface of prestressing strand

$d_{b}=$ strand diameter

$E=$ modulus of elasticity

$E_{c}=$ modulus of elasticity of concrete

$E_{p}=$ modulus of elasticity of prestressing steel

$E_{r}=$ modulus of elasticity in the radial direction

$E_{z}=$ modulus of elasticity in the axial direction
$E_{\theta}=$ circumferential modulus of elasticity of cracked concrete

$f_{c e}=$ longitudinal stress in concrete

$f_{c i}^{\prime}=$ strength of concrete at transfer

$f_{c z}=$ axial stress in the concrete at a distance $\mathrm{z}$ from the free end

$f_{p j}=$ prestress prior to transfer

$f_{p i}=$ initial prestress

$f_{p z}=$ axial stress in the prestressing steel at a distance $z$ from the free end

$f_{r}=$ known stress in radial direction

$f_{t}=$ tensile strength of concrete

$f_{t r}=$ reduced tensile strength of concrete at the outer surface

$f_{\theta}=$ known stress in circumferential direction

$l_{t}=$ transfer bond length

$L_{c}=$ extent of radial cracking

$p=$ interface pressure

$P_{j}=$ jacking prestressing force

$r=$ radial distance

$r_{o}=$ radius of the unstressed prestressing strand

$r_{j}=$ radius of the prestressed prestressing strand at jacking

$r_{n}=$ radial distance to section $\mathrm{n}$

$R=$ radial distance to the inner boundary of elastic uncracked section

$t=$ step size

$u=$ radial displacement

$u_{0}=$ radial displacement of outer surface of steel cylinder

$u_{j}=$ radial displacement of inner surface of concrete cylinder

$u_{n}=$ radial displacement at section $\mathrm{n}$

$u_{j}=$ radial displacement of inner surface of cracked concrete 


$$
\begin{aligned}
z= & \text { distance from the free end of the } \\
& \text { prestressing steel } \\
\varepsilon= & \text { concrete strain } \\
\varepsilon_{c z}= & \text { axial strain of concrete at a distance } \mathrm{z} \\
& \text { from free end } \\
\varepsilon_{p z}= & \text { axial strain of prestressing steel at a } \\
& \text { distance } \mathrm{z} \text { from the free end } \\
\varepsilon_{r}= & \text { strain in the radial direction } \\
\varepsilon_{z}= & \text { strain in the axial direction } \\
\varepsilon_{\theta}= & \text { strain in the circumferential direction } \\
\mu_{i}= & \text { coefficient of friction } \\
v= & \text { Poisson's ratio } \\
v_{c}= & \text { Poisson's ratio for concrete } \\
v_{p}= & \text { Poisson's ratio for prestressing steel } \\
\sigma_{r}= & \text { normal stress in radial direction } \\
\sigma_{z}= & \text { normal stress in axial direction } \\
\sigma_{\theta}= & \text { hoop stress acting in the } \\
& \text { circumferential direction } \\
v^{\prime} &
\end{aligned}
$$

\section{TABLES AND FIGURES}

\section{List of Tables:}

Table 1 - Properties of Test Beams

Table 2 - Part of Theoretical and Experimental Results

Table 3 - Variation of transfer length

\section{List of Figures:}

Fig. 1 - Relative Radial Displacement of Steel and Concrete

Fig. 2 - Isolated Steel Part from Sliced Element

Fig. 3 - Stresses Acting on Element

Fig. 4 - Possible Situations for Analysis

Fig. 5 - Definitions for Transfer Length

Fig. 6 - Theoretical and Experimental Curves for Beam A-1

Fig. 7 - Theoretical and Experimental Curves for Beam B-1

Fig.8 - Theoretical and Experimental Curves for Beam C-1

Fig.9 - Variation of Steel Stress in Transfer zone for $15.24 \mathrm{~mm}$ Strand with 20 $\mathrm{MPa}$ Concrete

Fig.10 - Variation of Steel Stress in Transfer zone for $15.25 \mathrm{~mm}$ Strand with 40 $\mathrm{MPa}$ Concrete

Fig. 11 - Stress Build-up in the Transfer zone 
Table 1 - Properties of Test Beams

\begin{tabular}{|c|c|c|c|c|c|c|c|}
\hline Group & \multicolumn{3}{|c|}{ A } & \multicolumn{2}{|c|}{ B } & \multicolumn{2}{|c|}{$\mathrm{C}$} \\
\hline Beam designation & A-1 & A-2 & A-3 & B-1 & B-2 & $\mathrm{C}-1$ & $\mathrm{C}-2$ \\
\hline $\begin{array}{c}\text { Concrete Cylinder Strength * } \\
\qquad(\mathrm{MPa})\end{array}$ & 19.8 & 22.5 & 19.7 & 37.5 & 36.2 & 22.4 & 23.5 \\
\hline Strand Diameter $(\mathrm{mm})$ & \multicolumn{3}{|c|}{12.7} & \multicolumn{2}{|c|}{12.7} & \multicolumn{2}{|c|}{15.24} \\
\hline Side Cover (mm) & \multicolumn{3}{|c|}{40} & \multicolumn{2}{|c|}{40} & \multicolumn{2}{|c|}{39} \\
\hline Bottom Cover (mm) & \multicolumn{3}{|c|}{40} & \multicolumn{2}{|c|}{40} & \multicolumn{2}{|c|}{39} \\
\hline Spacing $(\mathrm{mm})$ & \multicolumn{3}{|c|}{93} & \multicolumn{2}{|c|}{93} & \multicolumn{2}{|c|}{93} \\
\hline Leg Width (mm) & \multicolumn{3}{|c|}{185} & \multicolumn{2}{|c|}{185} & \multicolumn{2}{|c|}{185} \\
\hline Flange width (mm) & \multicolumn{3}{|c|}{400} & \multicolumn{2}{|c|}{400} & \multicolumn{2}{|c|}{400} \\
\hline Flange Depth (mm) & \multicolumn{3}{|c|}{300} & \multicolumn{2}{|c|}{300} & \multicolumn{2}{|c|}{300} \\
\hline Total Depth (mm) & \multicolumn{3}{|c|}{400} & \multicolumn{2}{|c|}{400} & \multicolumn{2}{|c|}{400} \\
\hline
\end{tabular}

* Age : At transfer 4 days

Table 2 - Part of Theoretical and Experimental Results

\begin{tabular}{|c|c|c|c|c|c|}
\hline \multirow{2}{*}{ Group } & \multicolumn{2}{|c|}{$\begin{array}{c}\text { No of Transfer } \\
\text { Lengths Measured }\end{array}$} & \multirow{2}{*}{ Theoretical } & \multicolumn{3}{|c|}{ Experimental } \\
\cline { 3 - 6 } & & & Minimum & Average & Maximum \\
\cline { 3 - 6 } & & & 426 & 552 & 741 \\
\hline A & 12 & 515 & 274 & 356 & 433 \\
\hline B & 8 & 382 & 771 & 798 & 843 \\
\hline C & 8 & 842 & & & \\
\hline
\end{tabular}

Note: Total number of results is 52 . 
Table 3 - Variation of transfer length

\begin{tabular}{|c|c|c|c|c|c|c|c|c|}
\hline Case & $d_{b}(m m)$ & $c_{y}(\mathrm{~mm})$ & $f_{c i}^{\prime} *(M P a)$ & $\left|f_{p j}(M P a)\right|$. & $f_{p i}(M P a)$ & $f_{c e}(M P a)$ & $l_{t}(\mathrm{~mm})$ & $l_{t} / d_{b}$ \\
\hline 1 & 15.24 & 20 & 20 & 1300 & 1214 & 6 & 1956 & 128 \\
\hline 2 & 15.24 & 20 & 20 & 1300. & 1130 & 12 & 1982 & 130 \\
\hline 3 & 15.24 & 20 & 20 & 900 & 817 & 6 & 918 & 60 \\
\hline 4 & 15.24 & 20 & 20 & 900 & 737 & 12 & 935 & 61 \\
\hline 5 & 15.24 & 40 & 20 & 1300 & 1214 & 6 & 863 & 57 \\
\hline 6 & 15.24 & 40 & 20 & 1300 & 1130 & 12 & 876 & 57 \\
\hline 7 & 15.24 & 40 & 20 & 900 & 817 & 6 & 469 & 31 \\
\hline 8 & 15.24 & 40 & 20 & 900 & 736 & 12 & 477 & 31 \\
\hline 9 & 15.24 & 20 & 40 & 1300 & 1239 & 6 & 1377 & 90 \\
\hline 10 & 15.24 & 20 & 40 & 1300 & 1178 & 12 & 1388 & 91 \\
\hline 11 & 15.24 & 20 & 40 & 900 & 841 & 6 & 647 & 42 \\
\hline 12 & 15.24 & 20 & 40 & 900 & 783 & 12 & 654 & 43 \\
\hline 13 & 15.24 & 40 & 40 & 1300 & 1239 & 6 & 609 & 40 \\
\hline 14 & 15.24 & 40 & 40 & 1300 & 1178 & 12 & 614 & 40 \\
\hline 15 & 15.24 & 40 & 40 & 900 & 841 & 6 & 332 & 22 \\
\hline 16 & 15.24 & 40 & 40 & 900 & 783 & 12 & 336 & 22 \\
\hline 17 & 9.53 & 20 & 20 & 1300 & 1214 & 6 & 479 & 50 \\
\hline 18 & 9.53 & 20 & 20 & 1300 & 1129 & 12 & 483 & 51 \\
\hline 19 & 9.53 & 20 & 20 & 900 & 814 & 6 & 306 & 32 \\
\hline 20 & 9.53 & 20 & 20 & 900 & 731 & 12 & 312 & 33 \\
\hline 21 & 9.53 & 40 & 20 & 1300 & 1213 & 6 & 294 & 31 \\
\hline 22 & 9.53 & 40 & 20 & 1300 & 1130 & 12 & 302 & 32 \\
\hline 23 & 9.53 & 40 & 20 & 900 & 814 & 6 & 267 & 28 \\
\hline 24 & 9.53 & 40 & 20 & 900 & 731 & 12 & 271 & 28 \\
\hline 25 & 9.53 & 20 & 40 & 1300 & 1239 & 6 & 335 & 35 \\
\hline 26 & 9.53 & 20 & 40 & 1300 & 1178 & 12 & 338 & 35 \\
\hline 27 & 9.53 & 20 & 40 & 900 & 839 & 6 & 216 & 23 \\
\hline 28 & 9.53 & 20 & 40 & 900 & 779 & 12 & 218 & 23 \\
\hline 29 & 9.53 & 40 & 40 & 1300 & 1238 & 6 & 210 & 22 \\
\hline 30 & 9.53 & 40 & 40 & 1300 & 1178 & 12 & 212 & 22 \\
\hline 31 & 9.53 & 40 & 40 & 900 & 839 & 6 & 192 & 20 \\
\hline 32 & 9.53 & 40 & 40 & 900 & 779 & 12 & 194 & 20 \\
\hline
\end{tabular}

* Cylinder strength 


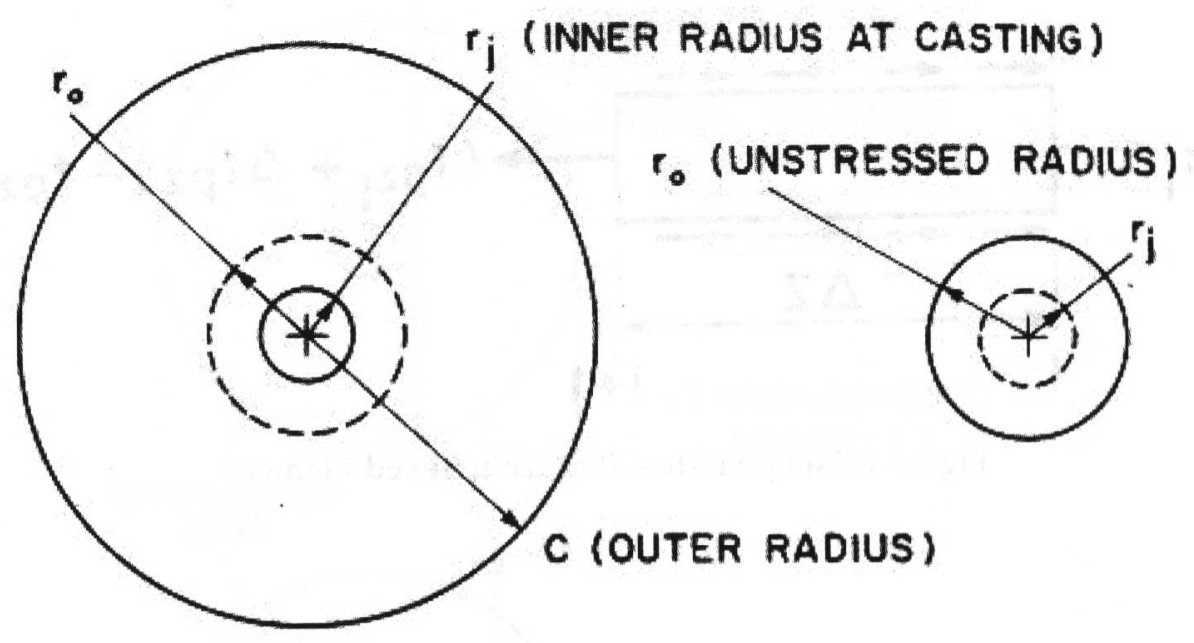

a) UNSTRESSED CONCRETE b) UNSTRESSED STEEL

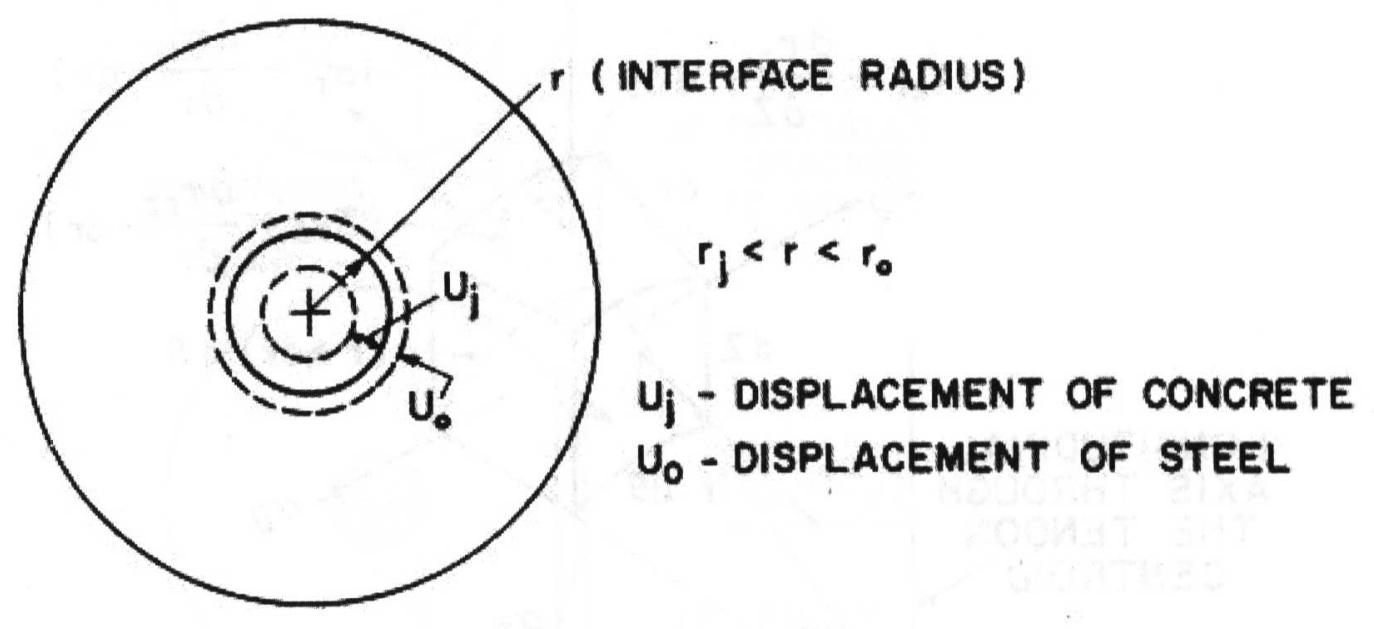

c) STRESSED COMPOSITE UNIT

Figure 1: Relative Radial Displacement of Steel and Concrete 


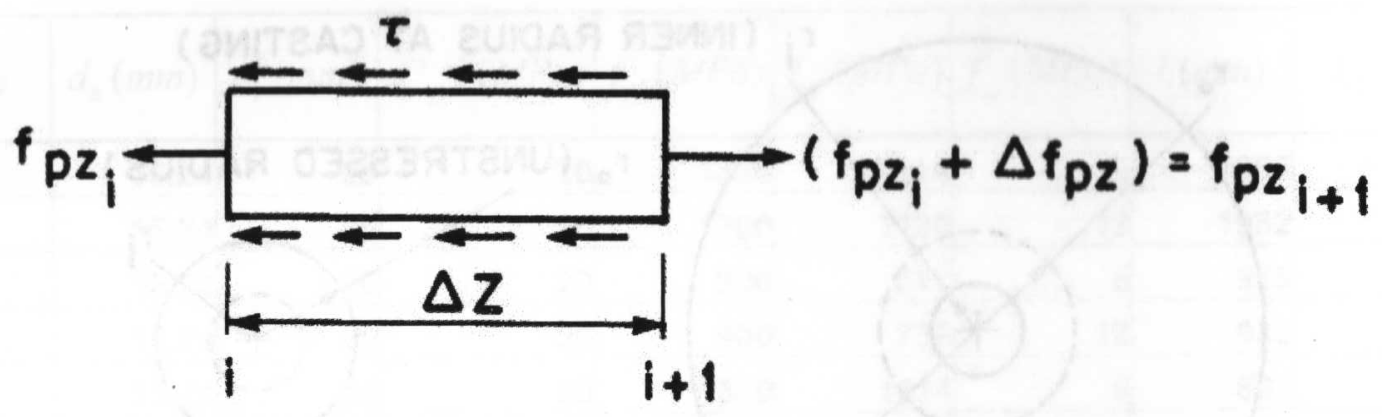

Figure 2: Isolated Steel Part from Sliced Element

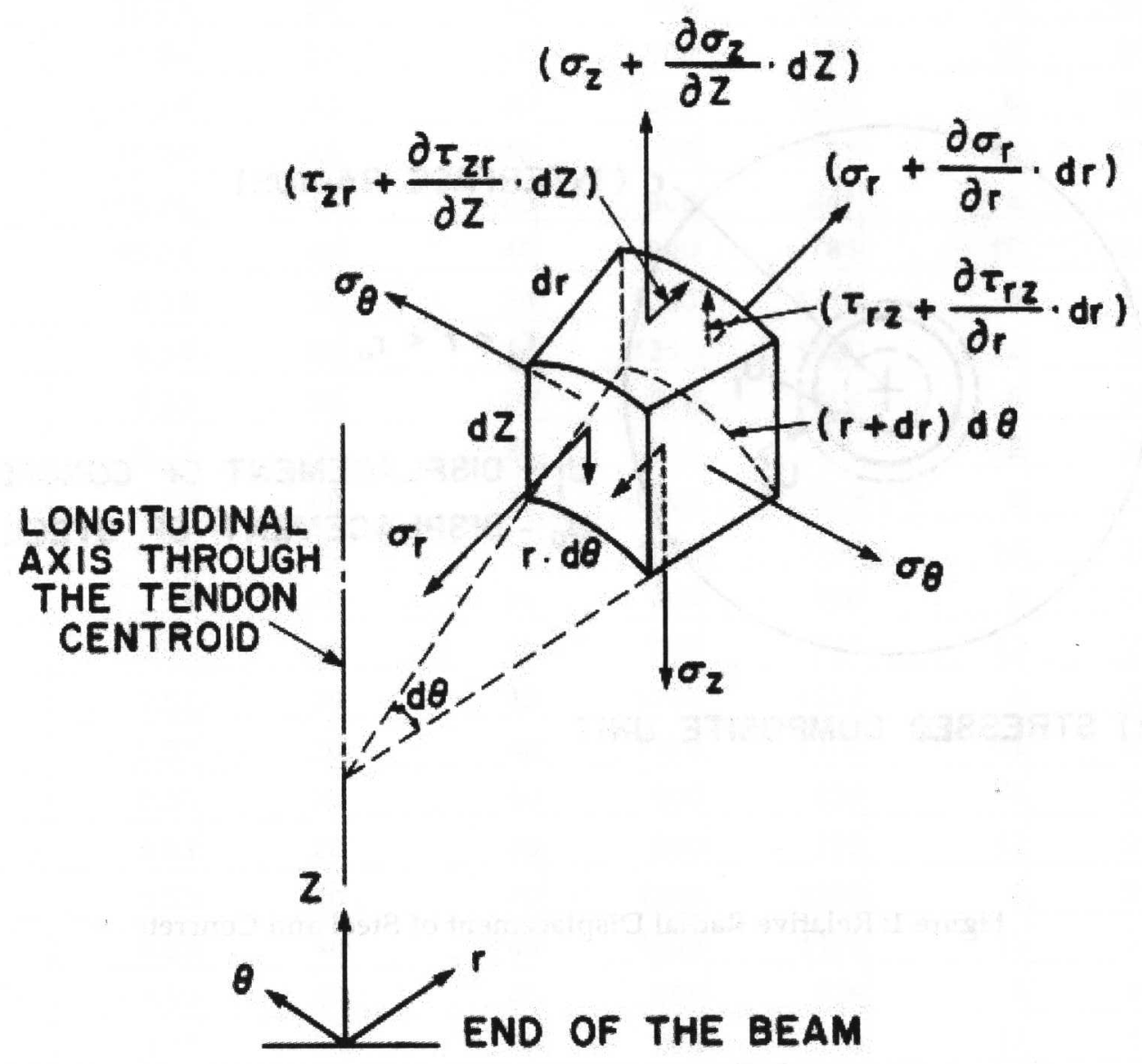

Figure 3: Stresses Acting on Element 


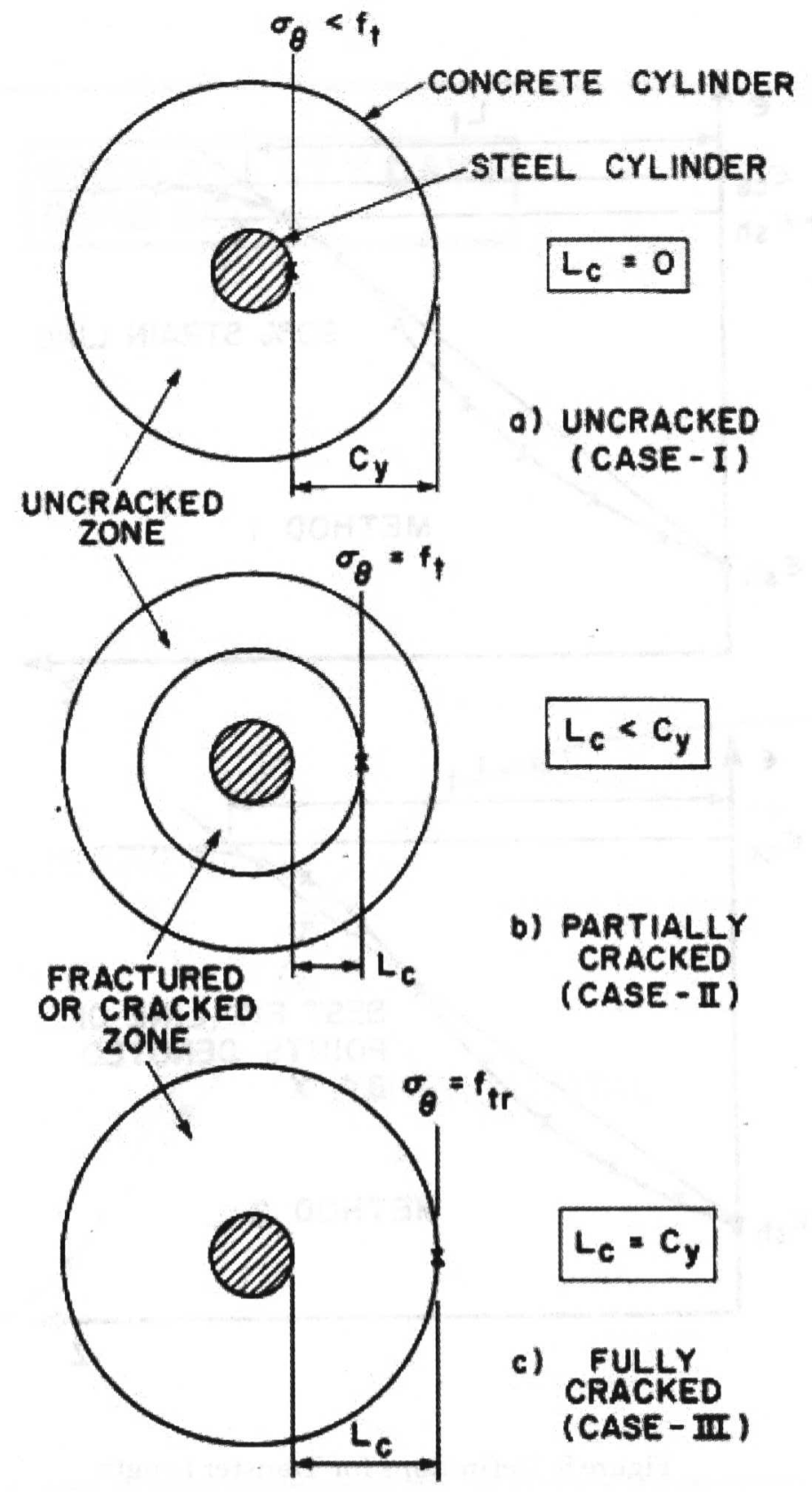

Figure 4: Possible Situations for Analysis 

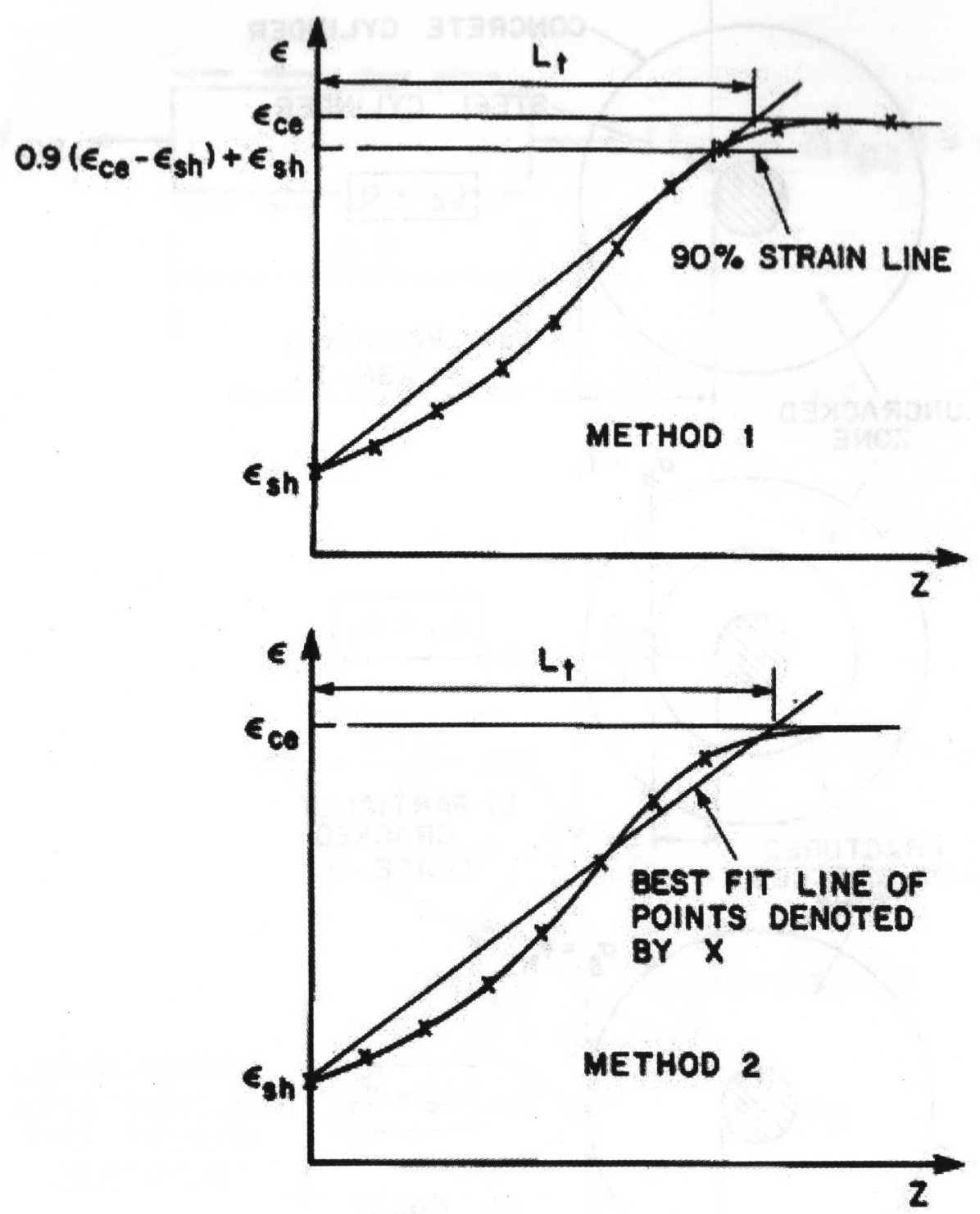

Figure 5: Definitions for Transfer Length 


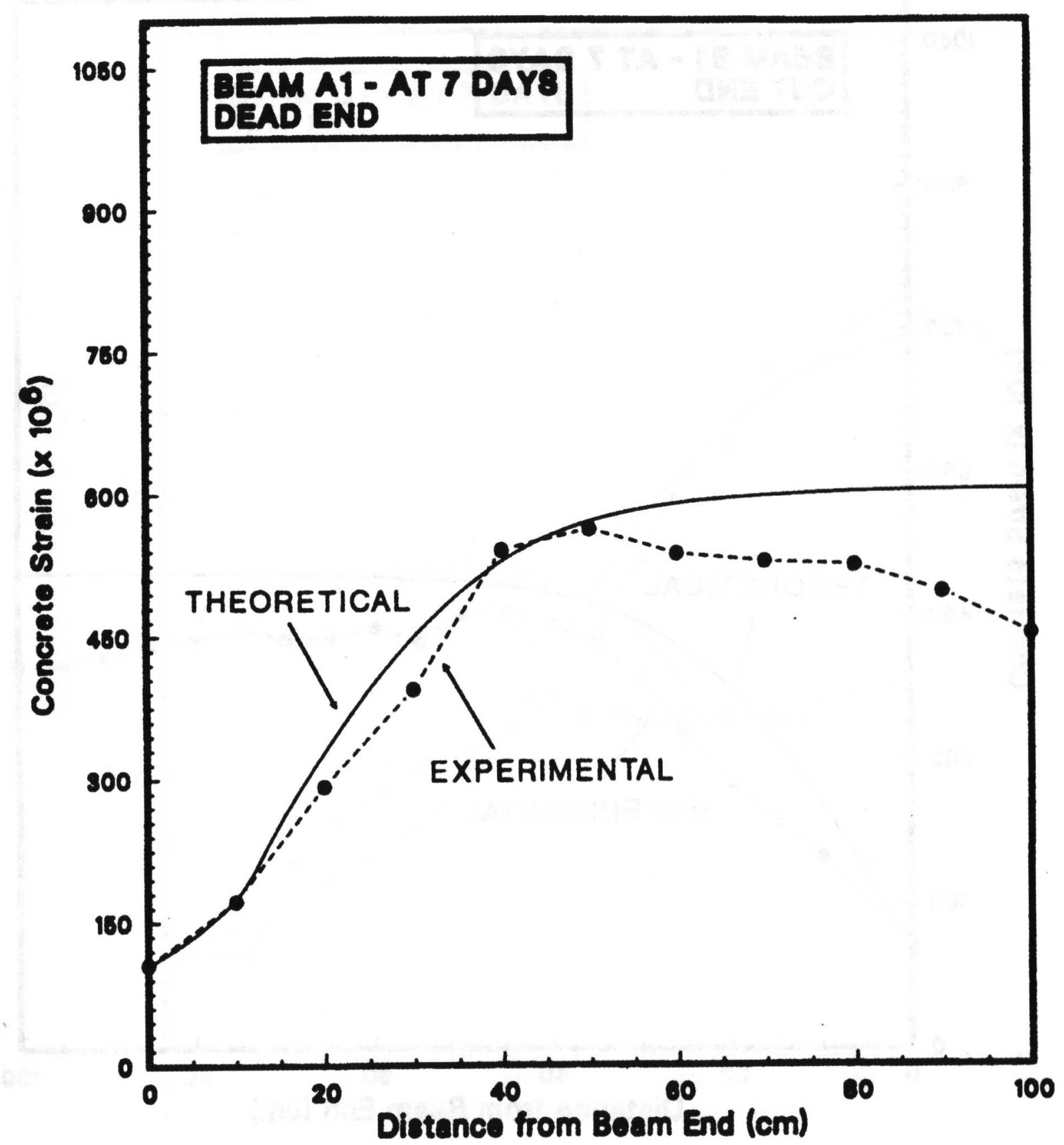

Figure 6 - Theoretical and Experimental Curves for Beam A-1 


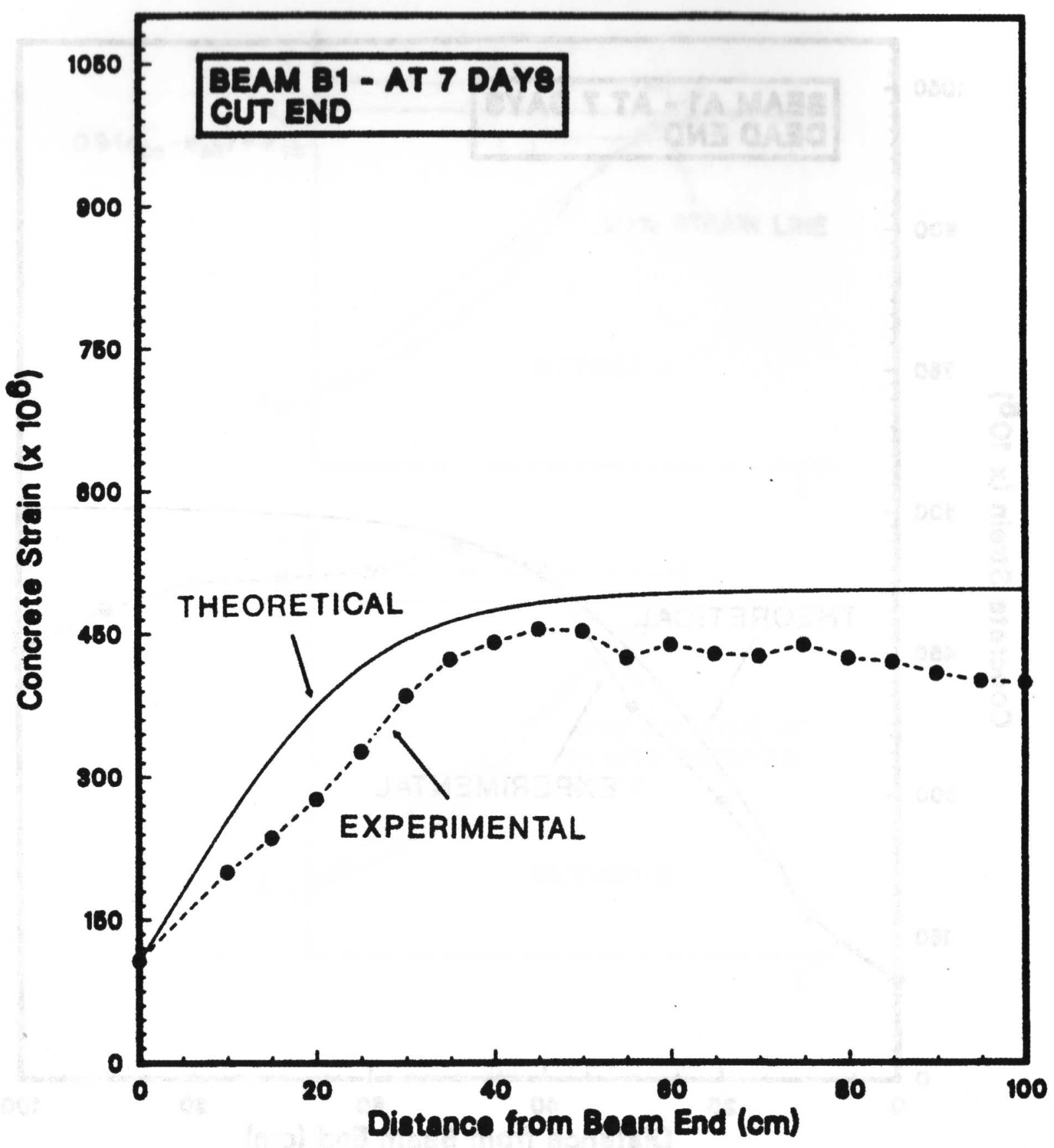

Figure 7 - Theoretical and Experimental Curves for Beam B-1 


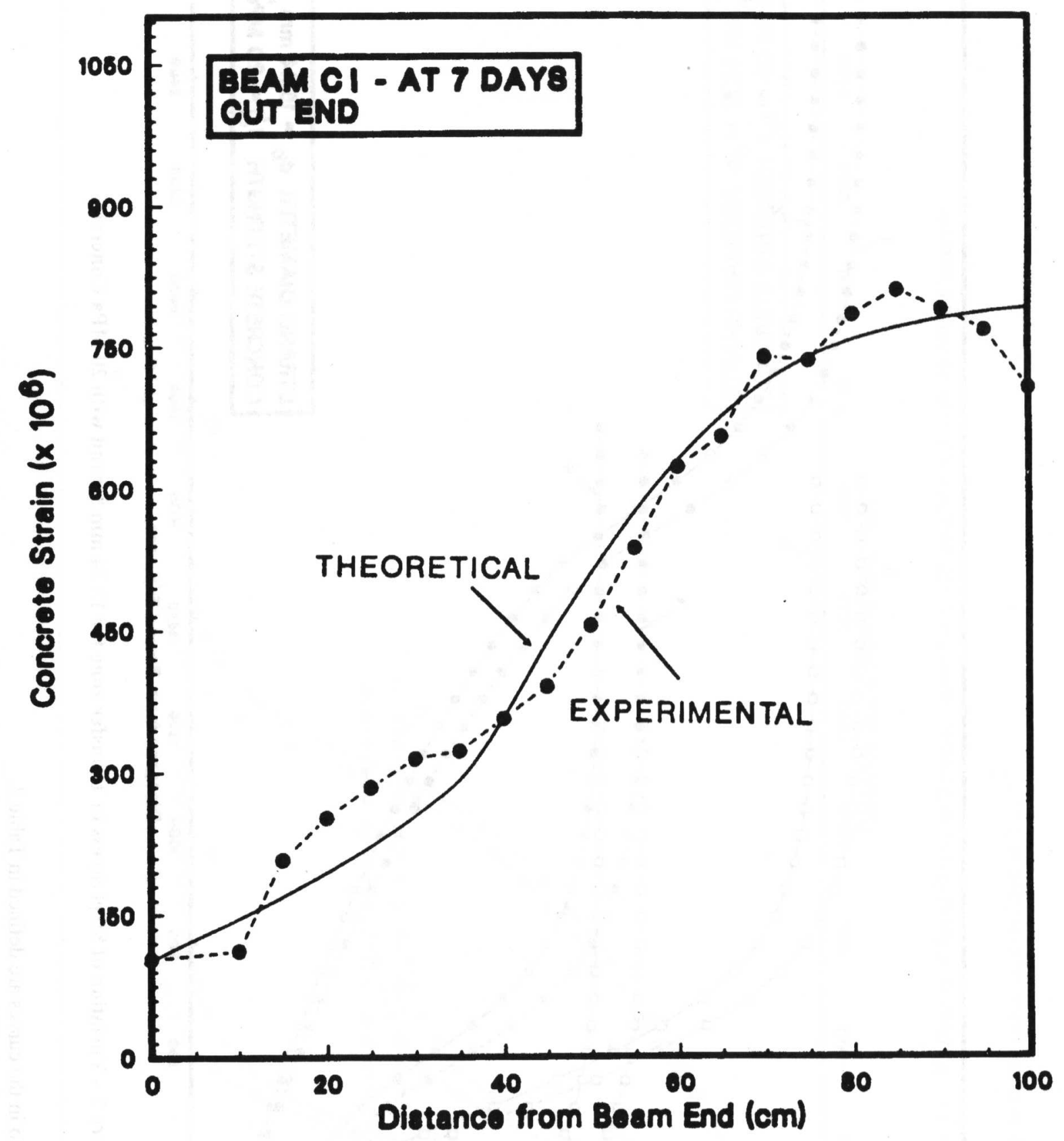

Figure 8 - Theoretical and Experimental Curves for Beam C-1 


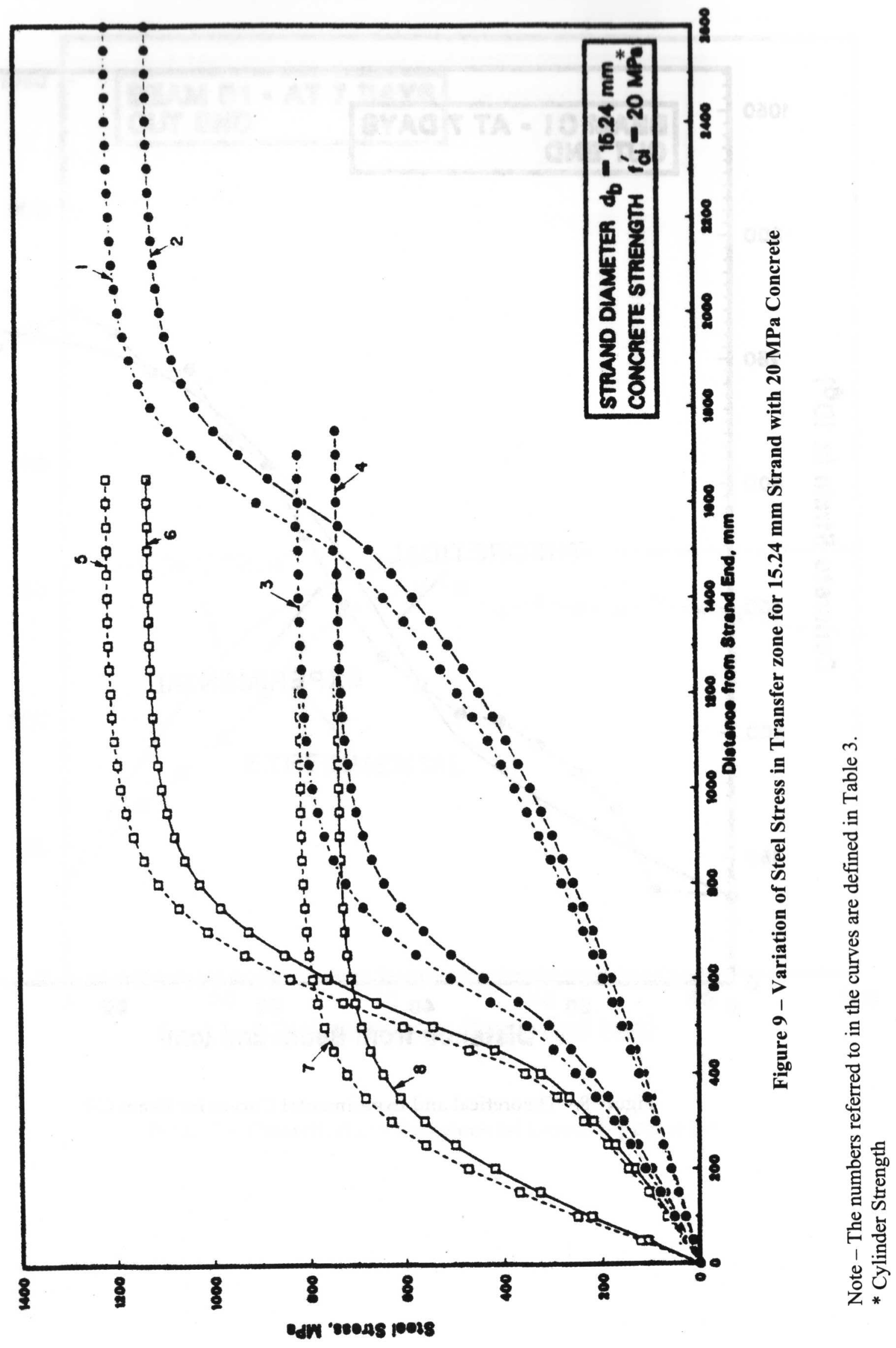




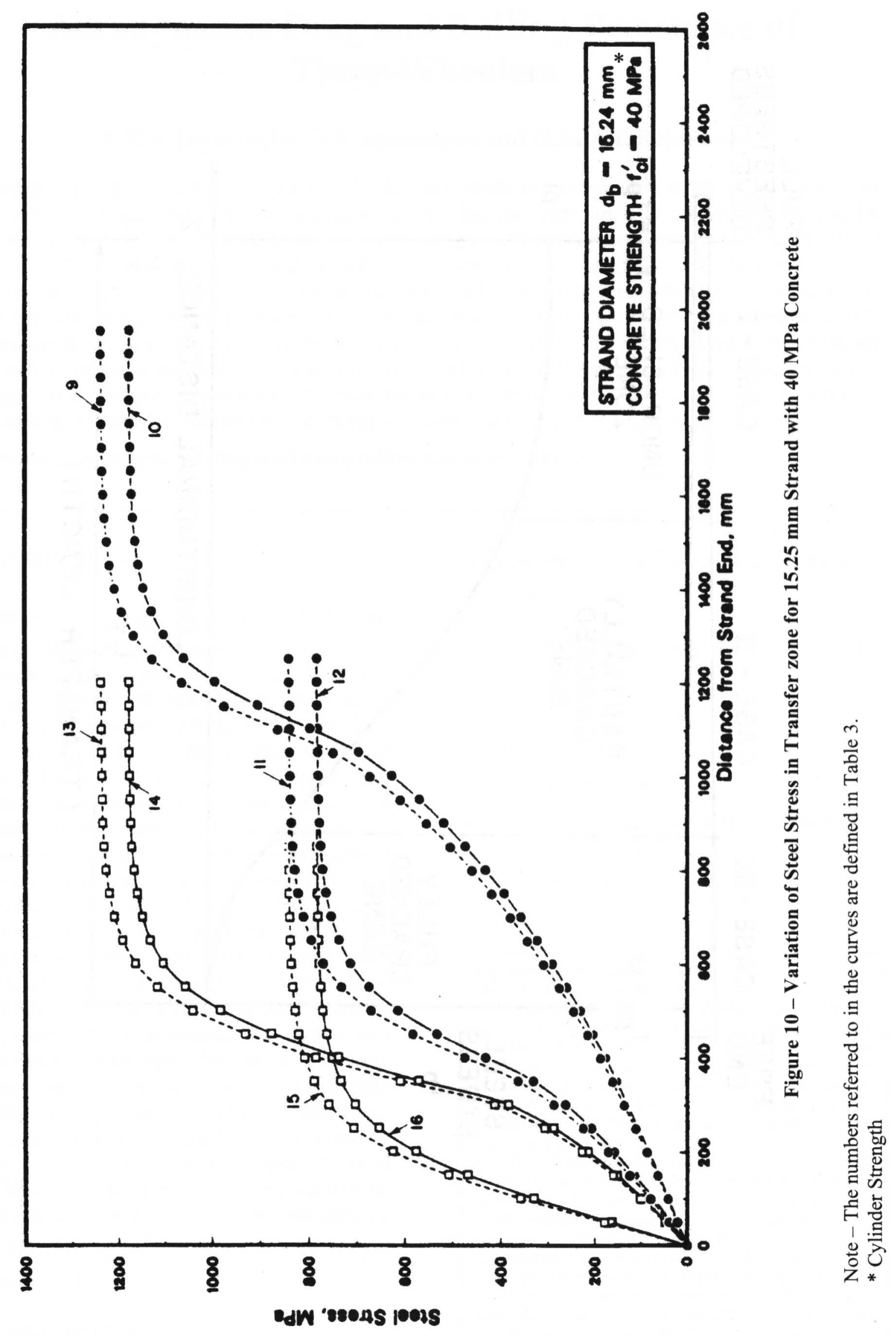




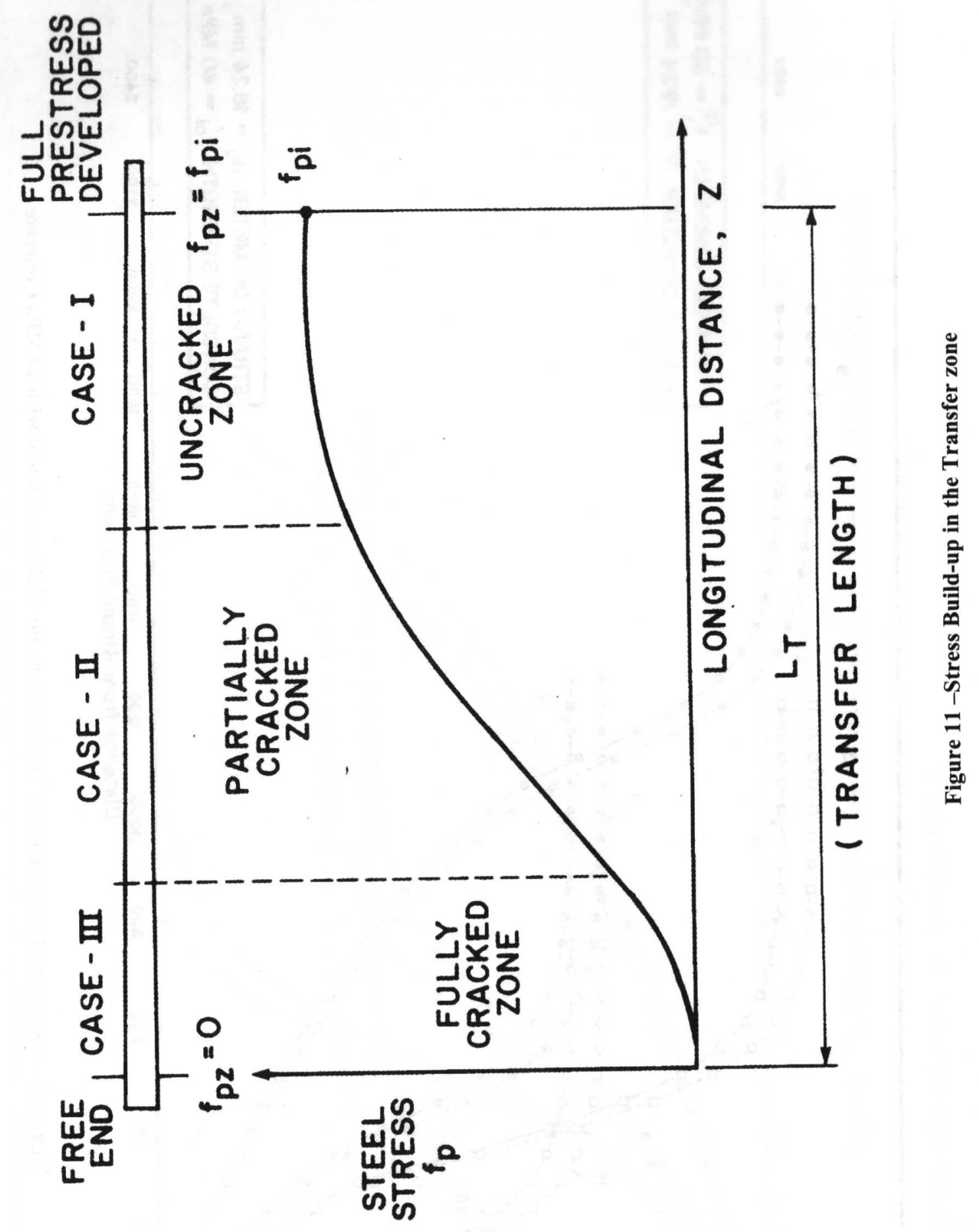

